\title{
PELAKSANAAN RELATIONSHIP MARKETING DAN CORPORATE SOCIAL RESPONSIBILITY DALAM UPAYA MENINGKATKAN LOYALITAS PELANGGAN INDOSAT
}

\author{
Sri Anik \\ Fakultas Ekonomi Universitas Islam Sultan Agung Semarang \\ e-mail: srianieks@yahoo.co.id \\ Andina Juhara \\ Fakultas Ekonomi Universitas Islam Sultan Agung Semarang
}

\begin{abstract}
Come at the global marketing requires companies to be more creative and be more observant in serving customers to achieve high sustainable business (sustainability), so it takes efforts beyond than just improve the quality and production of goods / services. Services and provision of value-added are the key words of modern marketing, and implementation of relationship marketing and corporate social responsibility will be influential in increasing customer loyalty. This study used a sample of 100 respondents Indosat customers. Analysis of the data used : test the quality of data, test of classical assumption, multiple linear regression analysis, and test of hypothesis with $t$ test and coefficient of determination. Results with test of multiple linear regression showed relationship marketing variables into the biggest variables that affect customer loyalty, with the value of 0.677 and Corporate Social Responsibility variable has a value of 0.280 . From the test results obtained by the adjusted coefficient of determination R2 of $72.3 \%$. This suggests that $72,3 \%$ variation of customer loyalties explained by the model, while the rest $27,7 \%$ explained by variables outside the model.
\end{abstract}

Keywords: Relationship Marketing, Corporate Social Responsibility, Customer loyalty. 
Sri Anik

Andina Juhara
Jurnal Manajemen Bisnis Indonesia Vol. 1, Nomor 3, Juni 2014

\section{Pendahuluan}

Dalam era perdagangan bebas dewasa ini, perusahaan dituntut untuk menemukan dan membangun sistem manajemen yang mampu secara profesional meningkatkan rasa kepedulian pelanggannya kepada perusahaan, atau bisa dikatakan sebagai loyalitas. Pemasar sangat mengharapkan dapat mempertahankan pelanggannya dalam jangka panjang, bahkan jika mungkin untuk selamanya. Pelanggan yang loyal mempunyai kecenderungan lebih rendah untuk melakukan switching (berpindah merek), membuat positif word of mouth, dan seorang pelanggan yang loyal akan mengurangi usaha mencari pelanggan baru serta memberikan umpan balik positif kepada organisasi.

Keadaan umum perolehan pasar seluler di Indonesia masih dikuasai oleh Telkomsel. Tabel 1 menunjukkan bahwa secara keseluruhan, Indosat masih menduduki posisi kedua dengan perolehan $21,98 \%$ pengguna seluler di Indonesia.

\section{Tabel 1}

Pangsa Pasar Seluler GSM 2010

\begin{tabular}{|l|l|}
\hline Operator & Jumlah pelanggan \\
\hline PT Telkomsel, tbk & $45,6 \%$ \\
\hline PT Indosat, tbk & $21,98 \%$ \\
\hline PT Axiata, tbk & $20,02 \%$ \\
\hline PT Hutchitson & $7,94 \%$ \\
\hline PT Natrindo Seluler, tbk & $4,47 \%$ \\
\hline
\end{tabular}

Sumber: Majalah Swa, 2010

Dapat dilihat pada tabel 2 dibawah ini, bahwa pelanggan Indosat pada tahun 2008 mengalami peningkatan yang sangat besar yaitu 50\% dari tahun sebelumnya. Namun tahun 2009, Indosat mengalami penurunan pelanggan sebesar $10 \%$ dari tahun 2008 , dan mengalami pertumbuhan pelanggan yang sangat lambat. Penurunan jumlah pelanggan Indosat mengindikasikan bahwa loyalitas konsumen yang berkurang. 
Sri Anik

Andina Juhara
Jurnal Manajemen Bisnis Indonesia

Vol. 1, Nomor 3, Juni 2014

Tabel 2

Pertumbuhan Pelanggan Indosat 2007-2010

\begin{tabular}{|l|l|l|}
\hline Tahun & Pelanggan (juta) & Pertumbuhan (persen) \\
\hline 2007 & 24,5 & $*$ \\
2008 & 36,5 & 50 \\
2009 & 33,1 & -10 \\
2010 & 44,3 & 34 \\
\hline
\end{tabular}

Sumber : www.detikinet.com

Penelitian ini difokuskan pada studi kasus di PT Indosat, Tbk. Karena meskipun PT. Indosat, tbk telah menjalankan berbagai program marketing dan promosi, namun tampaknya belum terlalu berdampak pada meningkatnya loyalitas pelanggan. Hal ini dapat dilihat dari jumlah pelanggan setia Indosat yang berada di urutan kedua dan hanya berbeda 1,96\% dari pesaing terdekatnya (XL). Sedangkan jika dibandingkan dengan pemimpin pasar yaitu Telkomsel, berbeda cukup jauh.

Dalam survey yang dilakukan oleh Frontier Consulting Group, dalam Majalah Marketing, Februari 2010, menentukan Top Brand Index (TBI) yang terbentuk dari rata-rata nilai mind share, market share, commitment share. Mind share (Top of Mind-TOM) merujuk pada merk yang pertama kali muncul di benak konsumen ketika berbicara kategori tertentu. Market share (Last Usage) dilihat dari merek-merek yang terakhir dipergunakan responden. Komponen terakhir dari top brand adalah commitment share atau future intention yang merupakan cerminan keinginan konsumen untuk mengkonsumsi produk tersebut di masa datang. Dari hasil survei menunjukkan bahwa Top Brand Indeks Indosat masih berada di bawah dari Telkomsel.

Tujuan studi ini untuk memperoleh bukti empiris Relationship Marketing dan Corporate Social Responsibility dapat mempengaruhi loyalitas pelanggan produk seluler Indosat di wilayah Semarang 
Sri Anik

Andina Juhara
Jurnal Manajemen Bisnis Indonesia Vol. 1, Nomor 3, Juni 2014

\section{Landasan Teori dan Pengembangan Hipotesis}

\section{Loyalitas Pelanggan}

Perkembangan dunia telekomunikasi sangat pesat, ditunjukkan dengan adanya peningkatan jumlah pengguna jasa telekomunikasi di dunia mengalami peningkatan. Proporsi jumlah pengguna di Asia-Pasific dibandingkan total jumlah pengguna pun mengalami peningkatan. Keunggulan fitur teknologi hanya akan mendatangkan keuntungan sesaat, karena perusahaan pesaing akan melakukan hal yang sama. Keuntungan yang langggeng bisa diraih bila perusahaan mampu meraih basis pelanggan yang besar.

Loyalitas secara harfiah diartikan kesetiaan, yaitu kesetiaan seseorang terhadap suatu objek. Sedangkan menurut Jill Griffin (2005) :

"loyalty is defined as non-random purchase expressed over time by some decisionmaking unit."

Menurut Kotler dan Armstrong (2005), salah satu elemen penting dalam loyalitas adalah kemauan pelanggan untuk memberikan dukungan terhadap produk atau jasa perusahaan dengan cara mengkomunikasikan pengalamannya yang baik kepada orang lain (positive word of mouth). Ketika seorang pelanggan dari perusahaan mau merekomendasikan produk atau jasa perusahaan kepada orang lain, maka hal ini menunjukkan adanya loyalitas yang tinggi dalam diri pelanggan tersebut.

\section{Relationship Marketing}

Relationship Marketing berkembang dalam dunia bisnis karena para pelaku bisnis menyadari bahwa untuk mengembangkan dan mempertahankan suatu bisnis, tidak hanya dengan mendapat pelanggan yang banyak, tetapi juga bagaimana caranya mendapatkan pelanggan, memeliharanya dan mempertahankan pelanggan tersebut. Menurut Keegan, Duncan, dan Moriaty (1996) :

"Relationship Marketing is an approach to marketing with its customers that promote both the company's long-term growth and the customer's maximum satisfaction". 
Russel Winer (2005) berpendapat, jika perusahaan dapat mengkombinasikan kemampuan untuk merespon dan menyediakan permintaan pelanggan dengan baik, serta melakukan hubungan yang lebih intensif dengan pelanggan melalui peningkatan kualitas layanan pelanggan sesuai dengan permintaan pelanggan, maka perusahaan tersebut dapat mempertahankan pelanggannya untuk jangka panjang.

Kotler dan Amstrong (2005) memberikan definisi mengenai Relationship Marketing, hubungan transaksi antara penyedia jasa dan pelanggan berkelanjutan, tidak berakhir setelah penjualan selesai. Dengan kata lain, suatu kemitraan jangka panjang dengan pelanggan dan secara terus menerus sehingga diharapkan dapat terjadi bisnis ulangan (repeat business).

Darai uraian diatas, maka hipotesis yang diajukan sebagai berikut:

\section{H1: Ada pengaruh antara Relationship Marketing terhadap loyalitas pelanggan.}

Melihat konsep yang bertitik tolak bahwa perusahaan harus memelihara dan menjaga hubungannya dengan pelanggan agar terjadi hubungan jangka panjang yang menguntungkan kedua belah pihak, maka selain menjalankan Relationship Marketing, perusahaan juga dapat melaksanakan program tanggung jawab sosial (Corporate Social Responsibility). Corporate Social Responsibility (CSR) yang kini dilaksanakan oleh perusahaan-perusahaan adalah salah satu cara untuk menarik dan meningkatkan loyalitas pelanggan. Hal inilah yang menjadi modal non finansial bagi perusahaan dan bagi stakeholder-nya yang menjadi nilai tambah bagi perusahaan untuk dapat tumbuh secara berkelanjutan.

Dengan penjelasan diatas, maka hipotesis kedua yang diajukan sebagai berikut :

\section{H2: $\quad$ Adanya pengaruh Corporate Social Responsibility terhadap}

\section{loyalitas pelanggan.}

Hasil Survey "The Millenium Poll on CSR" (1999) yang dilakukan oleh Environics International (Toronto), Conference Board (New York) dan Prince of Wales Business Leader Forum (London) di antara 25.000 responden dari 23 negara menunjukkan bahwa dalam membentuk opini tentang perusahaan, $60 \%$ mengatakan bahwa etika bisnis, praktik terhadap karyawan, dampak terhadap lingkungan, yang merupakan bagian dari tanggung jawab sosial perusahaan (CSR) akan paling berperan. Lebih lanjut, sikap konsumen terhadap perusahaan yang dinilai tidak melakukan CSR adalah ingin "menghukum" (40\%) dan 50\% tidak akan 
Sri Anik

Andina Juhara
Jurnal Manajemen Bisnis Indonesia Vol. 1, Nomor 3, Juni 2014

membeli produk dari perusahaan yang bersangkutan dan/atau bicara kepada orang lain tentang kekurangan perusahaan tersebut. Riset yang dilakukan oleh Roper Search Worldwide menunjukkan $75 \%$ responden memberi nilai lebih kepada produk dan jasa yang dipasarkan oleh perusahaan yang memberi kontribusi nyata kepada komunitas melalui program pembangunan. Sekitar $66 \%$ responden juga menunjukan mereka siap berganti merek kepada merek perusahaan yang memiliki citra sosial yang positif. Hal ini membuktikan terjadinya perluasan "minat" konsumen dari produk menuju korporat.

\section{Kerangka Pemikiran}

Meningkatnya tingkat kepedulian kualitas kehidupan, harmonisasi sosial dan lingkungan ini juga mempengaruhi aktivitas dunia bisnis. Jackie Ambadar (2008) berpendapat bahwa dengan melakukan kegiatan CSR, perusahaan yang lebih peduli kepada lingkungan merupakan kesempatan untuk memperkuat hubungan antara perusahaan dengan konsumen, bahkan dapat dijadikan keunggulan kompetitif. Sesuai dengan landasan teori dan penelitian terdahulu yang telah dipaparkan, penelitian ini akan menguji pelaksanaan Relationship Marketing dan Corporate Social Responsibility dalam upaya meningkatkan loyalitas pelanggan GSM Indosat. Kerangka pemikiran teoritis dapat dilihat sebagai berikut:

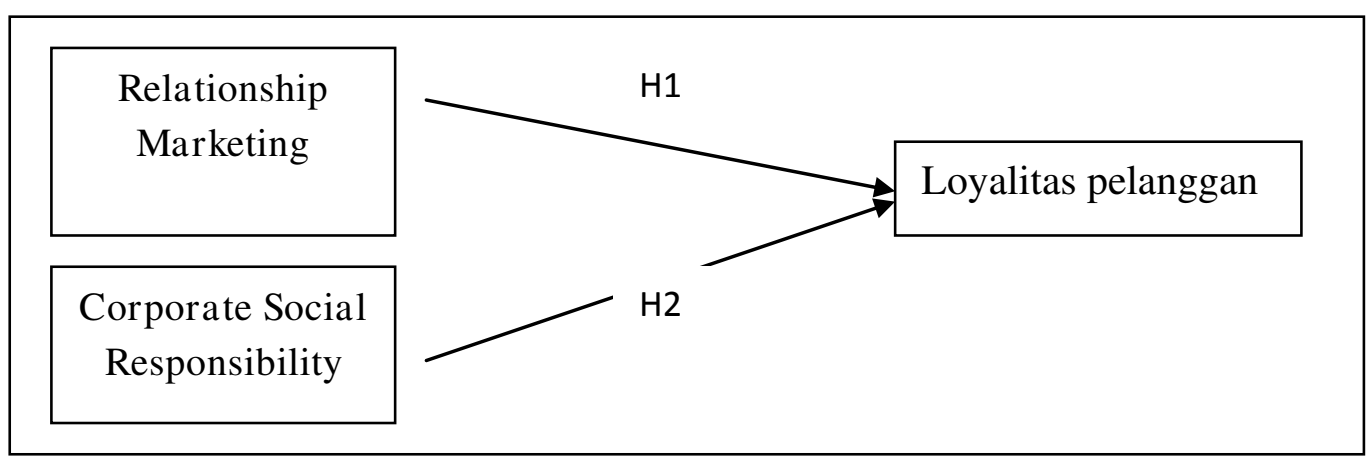

Gambar

Kerangka Pemikiran Penelitian

Sumber: Russel Winer (2005), Jackie Ambadar (2008) 
Sri Anik

Andina Juhara
Jurnal Manajemen Bisnis Indonesia Vol. 1, Nomor 3, Juni 2014

\section{Metode Penelitian}

\section{Populasi dan Sampel Penelitian}

Metode yang digunakan dalam pengambilan sampel adalah Non Probability Sampling, sedangkan teknik pengambilan sampelnya adalah Purposive Sampling dengan kriteria untuk pemilihan sampel adalah: (1) pengguna atau pernah menggunakan produk seluler GSM Indosat, (2) berusia lebih dari 15 tahun, dan (3) berdomisili atau menggunakan kartu seluler Indosat di kota Semarang. Sedangkan untuk menentukan jumlah sampel yang akan digunakan dengan menggunakan pendekatan Supranto (2001) sebagai berikut :

$$
\mathrm{n}=\frac{\mathrm{Z}^{2}}{4(\mathrm{moe})^{2}}
$$

Berdasarkan rumus diatas, maka diperoleh jumlah sampel sebanyak 96,04 dibulatkan menjadi 100 orang responden.

\section{Metode Pengumpulan data}

Data diperoleh dengan melakukan wawancara yang dilengkapi dengan instrumen kuesioner. Kuesioner yag diajukan kepada responden terdiri dari dua bagian yaitu bagian pertama tentang identitas responden dan bagian kedua tentang tanggapan variabel-variabel penelitian ( Relationship Marketing, Corporate Social Responsibility dan Loyalitas Pelanggan).

\section{Variabel dan Indikator}

Definisi operasional digunakan sebagai petunjuk tentang bagaimana suatu variabel diukur, dengan menggunakan indikator-indikator yang digunakan untuk mengukur variabel secara terperinci. Variabel serta indikator yang digunakan dalam penelitian ini adalah : 
Sri Anik

Andina Juhara
Jurnal Manajemen Bisnis Indonesia

Vol. 1, Nomor 3, Juni 2014

Tabel 3

Variabel penelitian dan Indikator

\begin{tabular}{|c|c|}
\hline Variabel & Indikator \\
\hline Loyalitas Pelanggan & $\begin{array}{l}\text { 1. Melakukan pembelian ulang (repeat } \\
\text { purchase). } \\
\text { 2. Merekomendasikan pada orang lain } \\
\text { (referalls). } \\
\text { 3. Melakukan word of mouth positif. }\end{array}$ \\
\hline Relationship Marketing & $\begin{array}{l}\text { 1. Menyediakan layanan pelanggan yang baik. } \\
\text { 2. Adanya program loyalitas. } \\
\text { 3. Membangun komunitas pelanggan yang } \\
\text { bermanfaat. }\end{array}$ \\
\hline $\begin{array}{l}\text { Corporate } \\
\text { Responsibility }\end{array}$ & $\begin{array}{l}\text { 1. Tanggungjawab kepada konsumen. } \\
\text { 2. Tanggungjawab kepada karyawan. } \\
\text { 3. Tanggungjawab kepada komunitas dan } \\
\text { lingkungan. }\end{array}$ \\
\hline
\end{tabular}

Skala pengukuran yang digunakan adalah skala likert $1 \mathrm{~s} / \mathrm{d} 5$ (skala $1=$ sangat tidak setuju dan skala 5 = sangat setuju)

\section{Teknik Analisis Data}

Data primer yang sudah terkumpul yang bersifat kualitatif akan dikonversikan menjadi kuantitatif, kemudian diuji validitas dan reliabilitas dan selanjutnya sebelum dianalisis dengan menggunakan Regresi Linear Berganda terlebih dahulu diuji asumsi klasi ( uji normalitas, uji multikolinearitas, dan uji heteroskedastisitas) 


\section{Hasil dan Pembahasan}

\section{Uji Validitas dan Reliabilitas}

Hasil uji validitas menunjukkan bahwa semua indikator dari masing-masing variabel menunjukkan $\mathrm{r}$ hitung $>\mathrm{r}$ tabel sehingga semua indikator penelitian adalah valid Reliabilitas sebenarnya adalah alat untuk mengukur suatu kuesioner yang merupakan indikator dari variabel. Menurut Ghozali (2001), suatu konstruk atau variabel dapat dikatakan reliable jika memiliki nilai Cronbach Alpha >0.6. Dari hasil uji reliabilitas menunjukkan nilai Cronbach Alpha variabel penelitian lebih besar dari 0,6 yaitu 0,871 maka dapat disimpulkan bahwa semua variabel dalam penelitian ini adalah reliabel.

\section{Uji Asumsi Klasik}

Sebelum melakukan pengujian dengan analisis regresi linier berganda, maka terlebih dahulu harus diuji penyimpangan asumsi klasik agar memberikan hasil yang Best Linear Unbiased Estimator Linear (BLUE) . Uji asumsi klasik adalah sebagai berikut:

\section{a. Uji Normalitas}

Dengan melihat tampilan grafik Normal Probability Plots terlihat bahwa titiknya menyebar disekitar garis diagonal serta penyebarannya mengikuti arah garis diagonal. Grafik tersebut menunjukkan bahwa model regresi layak dipakai karena memenuhi asumsi normalitas.

\section{b. Uji Multikolinieritas}

Untuk mendeteksi ada atau tidaknya multikolinearitas didalam model regresi adalah mempunyai nilai Variance Inflation Factor (VIF) $<10$ dan mempunyai nilai tolerance $>0,10$. Nilai tolerance masing-masing variable menunjukkan nilai yang lebih besar dari $10 \%$ atau $(0,1)$ dan nilai VIF masing-masing variabel adalah kurang dari 10. Jadi dapat disimpulkan bahwa tidak ada multikolinieritas antar variabel bebas dalam model regresi tersebut.

\section{c. Uji Heteroskedastisitas}

Dari grafik Scatterplot menunjukkan bahwa terlihat titik-titik yang menyebar secara acak serta tersebar baik diatas maupun dibawah angka nol pada sumbu y, hal ini dapat disimpulkan bahwa tidak terjadi heteroskedastisitas pada model regresi sehingga model regresi layak dipakai. 
Sri Anik

Andina Juhara
Jurnal Manajemen Bisnis Indonesia Vol. 1, Nomor 3, Juni 2014

\section{Analisis Regresi Linear Berganda}

Hasil uji regresi linier berganda tentang Pelaksanaan Relationship Marketing dan Corporate Social Responsibility Dalam Upaya Meningkatkan Loyalitas Pelanggan Indosat ini disajikan dalam tabel sebagai berikut:

\section{Tabel 4}

Hasil Uji Analisis Regresi Linier Berganda

\begin{tabular}{|c|l|l|l|}
\hline Variabel & $\begin{array}{l}\text { Unstandardized } \\
\text { Coefficients }\end{array}$ & $\mathbf{t}$ & Sig \\
\hline Constant & .392 & .558 & .578 \\
RM & .677 & 8.163 & .000 \\
CSR & .280 & 4.146 & .000 \\
\hline
\end{tabular}

Dependent variabel : loyalitas pelanggan

Dari tabel 4 diatas maka persamaan regresi linier berganda adalah sebagai berikut: $\quad \mathrm{Y}=$ $0.392+0.677 \mathrm{X} 1+0.280 \mathrm{X} 2+\mathrm{e}$

Dari persamaan tersebut menunjukkan bahwa : Nilai konstanta sebesar 0.392 dengan nilai sig. 0.578 (diatas 5\% atau 0.05). Hal ini berarti jika variabel Relationship Marketing (X1) dan Corporate Social Responsibility (X2) dianggap konstan maka loyalitas pelanggan adalah nol. Nilai koefisien variabel RM adalah positif 0.677 , hal ini berarti jika ada peningkatan variabel RM maka loyalitas pelanggan akan meningkat pula. Demikian juga nilai koefisien variabel CSR adalah positif 0.280 , hal ini berarti jika ada peningkatan variabel CSR maka loyalitas pelanggan akan meningkat pula.

\section{Uji Hipotesis dengan Uji T}

Uji hipotesis dengan uji t menunjukkan bahwa Hipotesis pertama (H1) diterima, terbukti sig $=0,000<0,005$, yang artinya Relationship Marketing berpengaruh signifikan terhadap loyalitas pelanggan, sehingga dapat dikatakan semakin tinggi Relationship Marketing akan meningkatkan loyalitas pelanggan. Hipotesis kedua $(\mathrm{H} 2)$ juga diterima, terbukti sig = $0,000<0,005$, artinya Corporate Social Responsibility berpengaruh signifikan terhadap loyalitas pelanggan, sehingga dapat dikatakan bahwa semakin tinggi Corporate Social Responsibility akan meningkatkan loyalitas pelanggan. 


\section{Koefisien Determinasi}

Adapun hasil uji koefisien determinasi dengan adjusted $\mathrm{R}^{2}$ menunjukkan bahwa nilai adjusted $\mathrm{R}^{2}$ adalah 0.723 , artinya $72,3 \%$ variasi loyalitas pelanggan bisa dijelaskan oleh variasi dari variabel independen, yaitu Relationship Marketing dan Corporate Social Responsibility. Sedangkan sisanya sebesar $27,7 \%$ dijelaskan oleh sebab-sebab yang lain diluar model.

\section{Pengaruh Relationship Marketing Terhadap Loyalitas Pelanggan}

Relationship Marketing berpengaruh signifikan terhadap loyalitas pelanggan. Hal ini dapat ditunjukkan dengan nilai signifikasi sebesar 0.000 yang lebih kecil dari 0.05 serta nilai koefisien regresi sebesar 0.677. Hasil penelitian ini mendukung penelitian Trisetia Wardenny (2005) yang menyatakan adanya pengaruh Relationship Marketing dengan loyalitas konsumen. Sehingga dapat disimpulkan bahwa semakin tinggi Relationship Marketing yang dilakukan PT Indosat di Semarang kepada pelanggan, maka akan semakin tinggi pula loyalitas pelanggan.

\section{Pengaruh Corporate Social Responsibility Terhadap Loyalitas Pelanggan}

Corporate Social Responsibility berpengaruh signifikan terhadap loyalitas pelanggan. Hal ini dapat ditunjukkan dengan nilai signifikasi sebesar 0.000 yang lebih kecil dari 0.05 serta nilai koefisien regresi sebesar 0.280. Hasil penelitian ini sesuai dengan hasil penelitian yang dilakukan oleh Kinorika Dewi (2007) yang menyatakan bahwa implementasi CSR akan menghasilkan good corporate image. Akumulasi dari citra positif perusahaan tersebut dapat memberikan manfaat dalam kaitannya dengan pelanggan, diantaranya adalah terciptanya adalah sikap positif pelanggan terhadap perusahaan yang akhirnya akan bermuara pada kesetiaan pelanggan terhadap perusahaan. Sehingga, dapat disimpulkan bahwa semakin tinggi Corporate Social Responsibility yang dirasakan manfaatnya oleh pelanggan atau lingkungan sekitarnya, maka akan semakin tinggi pula loyalitas pelanggan. 
Sri Anik

Andina Juhara
Jurnal Manajemen Bisnis Indonesia Vol. 1, Nomor 3, Juni 2014

\section{Simpulan Dan Saran}

Berdasarkan hasil penelitian, loyalitas pelanggan dapat ditingkatkan dengan peningkatan Relationship marketing yang diukur dengan menyediakan layanan yang baik, program loyalitas dan membangun komunitas yang bermanfaat dan peningkatan Corporate Social Responsibility yang diukur dengan tanggungjawab kepada konsumen, tanggungjawab kepada karyawan dan tanggungjawab kepada komunitas dan lingkungan.

Berdasarkan hasil penelitian perlu bagi PT Indosat untuk maksimalkan program Relationship Marketing dan meningkatkan kesadaran masyarakat akan adanya program-program yang dimiliki Indosat saat ini. Misalnya : Program loyalitas yang berbentuk poin yang saat ini waktunya terbatas untuk dapat diperpanjang. Selain itu setiap periode (setiap bulan) ada pemberitahuan kepada pelanggan tentang poin yang dimiliki dan cara penukaran poin, sehingga pelanggan dapat benar-benar merasakan manfaatnya, serta meningkatkan hubungan dengan pelanggan (misalnya: komunitas, join branding dengan bank, supermarket, bengkel dn lain-lain).

Dengan meningkatkan kualitas program CSR dan program yang lebih banyak lagi akan semakin meningkatkan loyalitas pelanggan Indosat. Misalnya :Pada program Indonesia Sehat dan Indonesia Belajar untuk dapat diperbesar ruang lingkupnya yaitu degan memperhatikan ke lingkungan yang agak terpencil dan lingkungan yang kurang diperhatikan, sehingga masyarakat yang benar-benar membutuhkan dapat merasakan manfaat yang besar dari kegiatan CSR Indosat. 
Sri Anik

Andina Juhara
Jurnal Manajemen Bisnis Indonesia Vol. 1, Nomor 3, Juni 2014

\section{Daftar Referensi}

AB, Susanto. 2003. Mengembangkan Corporate Social Responsibility di Indonesia, Jurnal Reformasi Ekonomi Volume 1. Jakarta.

Ambadar, Jackie. 2008. Corporate Social Responsibility Dalam Praktik Di Indonesia, Jakarta: Elex Media.

Alma, Buchari. 2004. Manajemen Pemasaran dan Pemasaran Jasa, Bandung: Alfabeta.

Chan, Syafruddin. 2003. Relationship Marketing : Inovasi Pemasaran yang Membuat Pelanggan Bertekuk Lutut, Jakarta: Gramedia Pustaka Utama.

Ghozali, Imam. 2001. Aplikasi Analisis Multivariat Dengan Program SPSS, Semarang: Badan Penerbit Universitas Diponegoro.

Griffin, Jill. 2005. Customer Loyalty (Menumbuhkan dan Mempertahankan Kesetiaan Pelanggan), Jakarta: Erlangga.

Keegan, Warren J, Sandra Moriarty, and Thomas Duncan. 1996. Marketing, New Jersey: Prentice Hall.

Kotler, Phillip dan Gary Armstrong. 2005. Manajemen Pemasaran, Jakarta: Index.

Lehman, Donald and Russel Winer. 2005. Analysis for Marketing Planning, Singapore: McGraw Hill Education.

Wibisono, Dermawan. 2003. Riset Bisnis, Jakarta: Gramedia Pustaka Utama.

Wibisono, Yusuf. 2007. Membedah Konsep dan Aplikasi CSR, Gresik: Penerbit Fascho.

Widjaja, Amin. 2008. Customer Relationship Management: Manajemen Hubungan Pelanggan, Konsep dan Kasus, Jakarta: Harvarindo.

Wijayanti, Ari. 2008. Strategi Meningkatkan Loyalitas Melalui Kepuasan Pelanggan.

Semarang 